\title{
Effect of Cutting Time, Temperature, and Calcium on Curd Moisture, Whey Fat Losses, and Curd Yield by Response Surface Methodology
}

\author{
C. C. Fagan, ${ }^{* 1}$ M. Castillo,† F. A. Payne,† C. P. O’Donnell, ${ }^{*}$ and D. J. O’Callaghanł \\ *Biosystems Engineering, UCD School of Agriculture, Food Science and Veterinary Medicine, University College Dublin, Dublin 4, Ireland \\ †Department of Biosystems and Agricultural Engineering, 128 C. E. Barnhart Building, Lexington, KY 40546-0276 \\ $\ddagger$ Moorepark Food Research Centre, Teagasc, Fermoy, Co. Cork, Ireland
}

\begin{abstract}
Response surface methodology was used to study the effect of temperature, cutting time, and calcium chloride addition level on curd moisture content, whey fat losses, and curd yield. Coagulation and syneresis were continuously monitored using 2 optical sensors detecting light backscatter. The effect of the factors on the sensors' response was also examined. Retention of fat during cheese making was found to be a function of cutting time and temperature, whereas curd yield was found to be a function of those 2 factors and the level of calcium chloride addition. The main effect of temperature on curd moisture was to increase the rate at which whey was expelled. Temperature and calcium chloride addition level were also found to affect the light backscatter profile during coagulation whereas the light backscatter profile during syneresis was a function of temperature and cutting time. The results of this study suggest that there is an optimum firmness at which the gel should be cut to achieve maximum retention of fat and an optimum curd moisture content to maximize product yield and quality. It was determined that to maximize curd yield and quality, it is necessary to maximize firmness while avoiding rapid coarsening of the gel network and microsyneresis. These results could contribute to the optimization of the cheese-making process.
\end{abstract}

Key words: light backscatter, curd moisture, whey fat, curd yield

\section{INTRODUCTION}

Optimization of cheese moisture, yield, and quality has become increasingly important to the dairy industry. These parameters are strongly affected by the extent of syneresis and syneresis kinetics. Syneresis is caused by the contraction of the curd matrix due to

Received May 1, 2007.

Accepted June 19, 2007.

${ }^{1}$ Corresponding author: colette.fagan@ucd.ie rearrangement of the paracasein network bonds. The rate of syneresis is determined by the pressure gradient developed in the network and by the flow resistance through the gel network. The tendency of a milk gel to exhibit syneresis is mainly determined by milk composition and pretreatment, the coagulation conditions, and the rheological properties of the gel at cutting. Dejmek and Walstra (2004) noted that, because of the importance of the syneresis process in the manufacture of cheese, it is useful to understand and quantitatively describe syneresis as a function of milk properties and process conditions. A number of studies have been published in which the effect of various factors on the rate and extent of syneresis was investigated. These studies have investigated the effect of factors such as temperature (Marshall, 1982), curd firmness (Johnson, et al., 2001), calcium chloride addition (Marshall, 1982; McMahon et al., 1984; Lucey and Fox, 1993), $\mathrm{pH}$ (McMahon et al., 1984), and cutting procedure (Johnston et al., 1998). Table 1 summarizes the results of a number of studies on the effect of the factors investigated in this study (temperature, cutting time, calcium) and their proposed consequences on syneresis.

Syneresis is very temperature dependent. Temperature affects syneresis in 2 ways because both coagulation temperature and syneresis temperature affect the rate and extent of syneresis. Coagulation temperature changes the half-life and rate of formation of bonds (Lagoueyte et al., 1994; Lucey, 2002; Mishra et al., 2005), which strongly affects the rheological and microstructural properties of the gel at cutting. van Vliet et al. (1991) reported that, in rennet gels, an increase in the coagulation temperature in the range of 20 to $35^{\circ} \mathrm{C}$ raised gel permeability $(\boldsymbol{B})$ as well as $\mathrm{d} B / \mathrm{d} t$, endogenous syneresis pressure, and the one-dimensional shrinkage of gels. Syneresis temperature also affects the rate of whey separation (Lawrence, 1959; Marshall, 1982). van den Bijgaart (1988) found that $\mathrm{d} B / \mathrm{d} t$ increased with increasing temperature. He stated that the faster increase of $B$ with time at higher temperatures must be caused by easier breaking of bonds and 
Table 1. The effect of temperature $(T)$, cutting time $\left(t_{\text {cut }}\right)$ and calcium chloride addition level $(C C A L)$ on curd syneresis

\begin{tabular}{|c|c|c|c|c|}
\hline Parameter & Proposed mechanism & Microscopic consequence & Macroscopic consequence & Reference \\
\hline \multicolumn{5}{|l|}{ Temperature } \\
\hline Increasing; $T<\sim 32^{\circ} \mathrm{C}$ & $\begin{array}{l}\text { Increased strength or } \\
\text { number of bonds }\end{array}$ & $\begin{array}{l}\text { Increased fusion of } \\
\text { casein micelles }\end{array}$ & $\begin{array}{l}\text { Increased whey expelled } \\
\text { Decreased TS released }\end{array}$ & $\begin{array}{l}\text { Lagoueyte et al. (1994) } \\
\text { Mishra et al. (2005) }\end{array}$ \\
\hline \multicolumn{5}{|l|}{$t_{\text {cut }}$} \\
\hline Late cut; $t_{\text {cut }}>$ optimum & $\begin{array}{l}\text { Increased strength or } \\
\text { number of bonds } \\
\text { Decreased } \\
\text { rearrangement }\end{array}$ & $\begin{array}{l}\text { Increased network } \\
\text { rigidity }\end{array}$ & $\begin{array}{l}\text { Decreased whey expelled } \\
\text { Increased curd moisture }\end{array}$ & Mishra et al. (2005) \\
\hline Increasing; $C C A L>\sim 10 \mathrm{~m} M$ & $\begin{array}{l}\text { Increased ionic } \\
\text { strength }\end{array}$ & $\begin{array}{l}\text { Decreased firmness, } \\
\text { weak gel }\end{array}$ & Decreased whey expelled & $\begin{array}{l}\text { McMahon et al. (1984) } \\
\text { Lucey and Fox (1993) }\end{array}$ \\
\hline
\end{tabular}

the disruption of junctions at greater temperatures. Therefore, the curd matrix has a greater capacity to rearrange and contract resulting in greater whey separation. The effect of calcium chloride addition on syneresis is more complex because addition of calcium chloride results in significant changes in ionic strength, colloidal calcium phosphate, and milk $\mathrm{pH}$, which in turn affect both syneresis and the formation and strength of the casein gel. Small additions of calcium chloride (up to $10 \mathrm{~m} M$ ) have generally been found to increase syneresis (Marshall, 1982), although some studies noted that small additions of calcium chloride had little or no effect on syneresis (Lawrence, 1959). At higher addition levels, the effect of calcium chloride has been observed to reduce syneresis.

A number of rheological and microstructural gel properties that are critical for adequate curd shrinkage and whey release (e.g., network rearrangement capability, coagulum firmness, permeability, and porosity) depend on appropriate cutting-time selection. As a result, cutting time greatly affects moisture, yield, and quality of cheese and whey fat losses. Johnston et al. (1998) also showed that cutting and stirring speeds could affect curd particle size and fat losses during syneresis. At constant cutting and stirring speeds, cutting the gel when it is too soft results in shattering of the fragile network, which increases curd fines and whey fat losses, thus, decreasing cheese yield (Lawrence, 1991). Although delaying the cutting time tends to induce the opposite effect, an excessive delay in cutting produces an overly firm gel, in which the net- work is unable to rearrange, which increases curd moisture content (Castillo et al., 2006b). Excessive moisture content, without the appropriate level of total solids retention, would result in an undesirable increase in yield, which could alter the ripening process, compromising cheese quality. Thus, there is likely an optimum time and hence firmness, for cutting the milk gel to optimize cheese yield and quality.

Although it is important to understand the effect of milk properties and processing conditions on curd shrinkage and whey release during cheese manufacturing, there is a lack of information on the effect of such factors and their interactions on syneresis. The first objective of this study was to investigate the effects of temperature, cutting time, and calcium chloride addition on cheese-making indices and on syneresis kinetics using response surface methodology. Light backscatter sensor technologies with a large field of view have proven successful for monitoring milk coagulation (Castillo et al., 2005) and syneresis (Fagan et al., 2007). Thus, a second objective was to monitor those 2 processing steps using a large field of view light backscatter sensor to study the effects of the experimental factors on the optical response and its derived parameters.

\section{MATERIALS AND METHODS}

\section{Experimental Design}

A 3-factor, fully randomized, spherical, central composite design (CCD) was used to study the effect of 
Table 2. Experimental factors and their levels used in the central composite rotatable experimental design

\begin{tabular}{lccc}
\hline $\begin{array}{l}\text { Factors } \\
\text { (coded value) }\end{array}$ & $\begin{array}{c}\text { Temperature } \\
\left({ }^{\circ} \mathrm{C}\right)\end{array}$ & $\begin{array}{c}\text { Added } \\
\mathrm{CaCl}_{2} \\
(\mathrm{~m} M)\end{array}$ & $\begin{array}{c}\text { Cutting time } \\
(\beta \text { value, } \\
\text { dimensionless })^{1}\end{array}$ \\
\hline-1.682 & 23.6 & 0.32 & 1.32 \\
-1 & 27.0 & 1.00 & 1.80 \\
0 & 32.0 & 2.00 & 2.50 \\
1 & 37.0 & 3.00 & 3.20 \\
1.682 & 40.4 & 3.68 & 3.68 \\
\hline
\end{tabular}

${ }^{1}$ Experimental cutting-time levels were selected as $\beta \times t^{*}{ }_{\max }$, where $t^{*}{ }_{\text {max }}$ was the time from enzyme addition to the inflection point of the light backscatter profile obtained using the CoAguLite sensor.

several significant coagulation and syneresis factors and gel properties at cutting on syneresis indices (e.g., curd yield, whey fat concentration, curd moisture content). The CCD consisted of a $2^{k}$ factorial $(k=3)$ with $2 k$ axial points and 6 center points (i.e., 20 runs in total) and was carried out in triplicate. Coagulation temperature $(\boldsymbol{T})$, calcium chloride addition level $(\boldsymbol{C C A L})$, and cutting-time level $(\boldsymbol{\beta})$ were selected as independent variables. The selected levels and coded values of the experimental factors are presented in Table 2. This experimental design allows for the estimation of curvature (second-order polynomial model) and can provide levels at which the independent variables will optimize a dependent variable.

Inline, continuous monitoring of milk coagulation and curd syneresis in a 7-L cheese vat was performed using 2 different light backscatter sensor technologies, the CoAguLite (CL) sensor (Reflectronics Inc., Lexington, KY) and the large field of view (LFV) sensor (Univ. Kentucky, Lexington). Experimental cutting-time levels were selected by light backscatter measurements using the CL sensor as described below.

\section{Milk Preparation and Coagulation}

Unpasteurized and unhomogenized milk obtained from a local Kentucky milk-processing plant was pasteurized at $65^{\circ} \mathrm{C}$ for $30 \mathrm{~min}$. Milk was analyzed for fat, protein, and TS content using a MilkoScan FT 120 (Foss Electric, Hillerød, Denmark). The average composition of the milk was determined as $3.7 \pm 0.3 \%, 3.5 \pm$ $0.1 \%$, and $12.2 \pm 0.3 \%$ for fat, protein, and TS contents, respectively. Calcium chloride was added to $7.20 \mathrm{~kg}$ of milk at the required level, and the milk was stirred for 3 min. Milk was adjusted to a $\mathrm{pH}$ of 6.5 using the method described by Fagan et al. (2007). Milk pH adjustment after $\mathrm{CaCl}_{2}$ addition ensured that any observed effect of calcium level on dependent variables was not due to an indirect effect of $\mathrm{CaCl}_{2}$ on milk $\mathrm{pH}$.

On the day of coagulation, milk was slowly heated to the target coagulation temperature $\pm 0.15^{\circ} \mathrm{C}$ using a water bath. Seven kilograms of the heated milk was added to the vat and left to equilibrate until thermal equilibrium was achieved. Coagulation temperature was controlled by water circulation via a water bath with a control accuracy of $\pm 0.01^{\circ} \mathrm{C}$ (Lauda, RM 20, Brinkmann Instrument Inc., Westbury, NY). Milk temperature was measured with a precision thermistor (model 5831A, Omega Engineering, Stanford, CT; resolution: $\pm 0.01^{\circ} \mathrm{C}$; accuracy: $\pm 0.2^{\circ} \mathrm{C}$ ). Chymosin (Chy-Max Extra; Chr. Hansen Inc., Milwaukee, WI) was added to $7 \mathrm{~kg}$ of milk in the vat at a level of 0.06 $\mathrm{mL} / \mathrm{kg}$ of milk, and the milk was stirred for $1 \mathrm{~min}$. Data acquisition for the CL and LFV sensors commenced upon addition of the enzyme; that is, at time $t_{\mathrm{c} 0}$ (subscript "c" denotes the coagulation monitoring period).

\section{Online Light Backscatter Monitoring Instrumentation}

The CL sensor (model 5, Reflectronics Inc.) was used to select the different experimental levels of cutting time. This sensor used near-infrared radiation at 880 $\mathrm{nm}$ and consisted of two $600-\mu \mathrm{m}$-diameter fibers. One fiber transmitted infrared radiation into the milk sample and the other fiber transmitted the radiation scattered by the milk particles to a silicon photodetector. Further details on the CL sensor and data acquisition system were presented previously by Castillo et al. (2006a) and Fagan et al. (2007).

The LFV sensor was a prototype designed at the University of Kentucky to monitor coagulation and syneresis. This sensor uses near-infrared light at 980 $\mathrm{nm}$, which is transmitted to the milk via a quartz rod, while a large-diameter glass window allows backscattered light to be collected over a large area and transmitted through a second quartz rod and a fiber optic cable to a miniature fiber optic spectrometer (model SD2000, Ocean Optics Inc., Dunedin, FL). Further details on the LFV sensor and data acquisition system were presented by Fagan et al. (2007).

The responses of the CL and LFV sensors were treated as follows. The initial voltage response $\left(\boldsymbol{V}_{\mathbf{0}}\right)$ was calculated by averaging the first minute of data. A light backscatter ratio $(\boldsymbol{R})$ was calculated by dividing the sensor output voltage by $V_{0}$. The first derivative $\left(R^{\prime}\right)$ of the light backscatter ratio profile was calculated by conducting linear least-squares regression on the most recently collected $4 \mathrm{~min}$ of data. The calculated slope was assigned to the midpoint of the data subset used. The second derivative $\left(R^{\prime \prime}\right)$ was calculated in a similar manner but using 60 data points to smooth the $R^{\prime \prime}$ profile. A number of optical parameters were derived from both the LFV and CL sensor response 
during coagulation and syneresis as outlined in Castillo et al. (2006a). The optical parameters investigated in this study are $\boldsymbol{t}_{\max }$, the time to the first maximum of $R^{\prime} ; \boldsymbol{t}_{2 \max }$, the time to the first maximum of $R^{\prime \prime} ; \boldsymbol{t}_{2 \min }$, the time to the first minimum of $R^{\prime \prime}$; and $\Delta \boldsymbol{R}_{\mathbf{s y n}}$, the percentage decrease in $R$ from cutting time to the end of syneresis $\left(\boldsymbol{t}_{\mathbf{s 8 5}}\right.$; subscript "s" denotes the syneresis monitoring period).

\section{Selection of Cutting-Time Levels and Cutting Procedure}

The CL sensor assisted the selection of the cutting time using the following equation proposed by Payne et al. (1993):

$$
t_{\text {cut }}=\beta t_{\text {max }}^{*},
$$

where $\beta$ was a constant and the asterisk indicates that $t_{\max }$ values used for cutting-time selection were derived from the CL sensor response. A number of different $\beta$ values $(1.3,1.8,2.5,3.2$, and 3.7), obtained in compliance with the experimental design shown in Table 2, were used to establish the range of target $t_{\text {cut }}$ values for the experiment. Because an increase in $\beta$ represents a delay in cutting, we will use the term "cutting time" $\left(\boldsymbol{t}_{\text {cut }}\right)$ instead of the less intuitive symbol $\beta$ during the discussion. The gel was cut when indicated by the CL data acquisition software. The curd was left to heal for $4.5 \mathrm{~min}$ before stirring $(10 \pm 0.02 \mathrm{rpm})$ was initiated (Servodyne mixer 50003-10, Cole Parmer Instrument Co., Vernon Hills, IL). The stirring process continued at this speed up to $85 \min \left(t_{\mathrm{s} 85}\right)$.

\section{Curd and Whey Sampling Procedure}

Homogeneous samples of curd and whey $(\sim 150 \mathrm{~mL})$ were removed for compositional analysis at $5 \mathrm{~min}$ from cutting $\left(\boldsymbol{t}_{\mathbf{s 5}}\right)$ and every 10 min thereafter up to $t_{\mathrm{s} 85}$ (i.e., 9 samples) according to the method described by Fagan et al. (2007) and Everard et al. (2007). Curd and whey samples were separated using a no. 200 stainless steel standard test sieve (Fisher Scientific, Hampton, NH) with a $75-\mu \mathrm{m}$ absolute pore size. The sieve characteristics were selected to ensure that whey fat globules were not retained by the sieve.

\section{Compositional Analysis of Curd and Whey and Calculation of Component Recoveries and Curd Yields}

Approximately $3 \mathrm{~g}$ of curd and $5 \mathrm{~g}$ of whey were weighed into preweighed aluminum dishes using an analytical balance with a resolution of $0.1 \mathrm{mg} \pm 0.2$
Table 3. List of cheese-making indices evaluated in this study and equations for their calculation

\begin{tabular}{ll}
\hline Parameter & Calculation $^{1,2}$ \\
\hline Total whey fat loses, g & $W F L=\frac{(M-C) \cdot F_{w}}{100}$ \\
Curd yield, wet basis, \% & $C Y_{w b}=\frac{C}{M} 100$ \\
Curd yield, dry basis, \% & $C Y_{d b}=\frac{C \cdot T S_{c}}{M \cdot T S_{m}} 100$ \\
Curd fat retention, \% & $C F R=\frac{M \cdot F_{m}-W \cdot F_{w}}{M \cdot F_{m}} 100$
\end{tabular}

${ }^{1} C=$ curd weight $(\mathrm{g}) ; M=$ milk weight $(\mathrm{g}) ; W=$ whey weight $(\mathrm{g}) ;$ $F_{\mathrm{m}}=$ milk fat $(\%) ; F_{\mathrm{w}}=$ whey fat $(\%) ; T S_{\mathrm{c}}=\operatorname{curd} \mathrm{TS}(\%) ; T S_{\mathrm{m}}=$ milk TS (\%).

${ }^{2}$ Values used for parameters $F_{\mathrm{w}}$, and $T S_{\mathrm{c}}$ corresponded to recorded values at $t=85 \mathrm{~min}$.

mg (AE260, Mettler-Toledo Inc., Columbus, OH) for determination of TS of curd and whey at each sampling time. The dishes were dried in a convection oven at $102^{\circ} \mathrm{C}$ until they reached a constant weight $(\sim 15 \mathrm{~h})$. Each sample was analyzed in triplicate. Chemical composition of whey (fat, protein, and TS content) was determined in triplicate using a previously calibrated MilkoScan FT120 (Fagan et al., 2007). Curd moisture and whey fat contents (\%) during syneresis were defined as $\boldsymbol{C M}_{\mathbf{t}}$ and $\boldsymbol{W F}_{\mathbf{t}}$, respectively, where $t$ was the time from cutting at which the sample was taken. Total whey fat losses (WFL, g) at the end of each experiment were calculated as shown in Table 3 . The curd yield $(\boldsymbol{C Y})$ for each experiment was computed using 2 equations as detailed in Table 3. Curd yield on a wet basis $\left(\boldsymbol{C} \boldsymbol{Y}_{\mathbf{w b}}\right)$ was influenced not only by the TS retained in the curd but also by the curd moisture content. Curd yield on a dry basis $\left(\boldsymbol{C Y}_{\mathbf{d b}}\right)$, however, provided information relating to the TS retained in the curd. The percentage of curd fat retention $(\boldsymbol{C F R})$ was also calculated as shown in Table 3.

\section{Statistical Analysis}

Statistical analysis was carried out using the RSREG procedure of SAS (version 9.1, 2002-2003; SAS Institute, Cary, NC) to determine significant differences $(P<0.05)$. The RSREG procedure uses the method of least squares to fit quadratic response surface regression models and to obtain information about the fit in the form of an ANOVA. Response surface regression models were generated for each of the dependent variables. Three-dimensional response surface plots of each predicted parameter were also generated. 
Table 4. Analysis of variance ${ }^{1}$ and $F$-statistic for the syneresis indices

\begin{tabular}{lcccccccc}
\hline & \multicolumn{7}{c}{ Syneresis indices } \\
\cline { 2 - 8 } Factors & $W F_{5}$ & $W F_{85}$ & $W F L$ & $C M_{5}$ & $C M_{85}$ & $C Y_{\mathrm{wb}}$ & $C Y_{\mathrm{db}}$ & $C F R$ \\
\hline$T$ & $-0.38^{* * * *}$ & $-0.47^{* * *}$ & $-19^{* * *}$ & $2.5^{* *}$ & $-1.1^{\mathrm{NS}}$ & $-1.3^{*}$ & $2.0^{*}$ & $11^{* * *}$ \\
Cutting time $(\beta)$ & $-0.82^{* *}$ & $-0.39^{*}$ & $-17^{*}$ & $1.7^{\mathrm{NS}}$ & $0.35^{\mathrm{NS}}$ & $2.8^{\mathrm{NS}}$ & $0.29^{\mathrm{NS}}$ & $1.4^{\mathrm{NS}}$ \\
$C C A L$ & $-0.61^{* *}$ & $-0.03^{\mathrm{NS}}$ & $-1.6^{\mathrm{NS}}$ & $1.1^{\mathrm{NS}}$ & $0.22^{\mathrm{NS}}$ & $2.6^{\mathrm{NS}}$ & $0.51^{\mathrm{NS}}$ & $0.51^{\mathrm{NS}}$ \\
$\beta \times \beta$ & $0.03^{\mathrm{NS}}$ & $-0.005^{\mathrm{NS}}$ & $-0.22^{\mathrm{NS}}$ & $0.16^{\mathrm{NS}}$ & $-0.32^{\mathrm{NS}}$ & $0.05^{\mathrm{NS}}$ & $0.29^{\mathrm{NS}}$ & $0.80^{\mathrm{NS}}$ \\
$\beta \times T$ & $0.02^{*}$ & $0.01^{* *}$ & $0.55^{* *}$ & $-0.12^{\mathrm{NS}}$ & $0.05^{\mathrm{NS}}$ & $-0.05^{\mathrm{NS}}$ & $-0.49^{\mathrm{NS}}$ & $-2.4^{* *}$ \\
$T \times T$ & $0.004^{* * *}$ & $0.007^{* * *}$ & $0.29^{* * *}$ & $-0.04^{* *}$ & $-0.008^{\mathrm{NS}}$ & $0.01^{\mathrm{NS}}$ & $-1.9^{\mathrm{NS}}$ & $-12^{* * *}$ \\
$C C A L \times \beta$ & $0.03^{\mathrm{NS}}$ & $0.01^{\mathrm{NS}}$ & $0.92^{\mathrm{NS}}$ & $0.55^{\mathrm{NS}}$ & $-0.22^{\mathrm{NS}}$ & $-0.70^{*}$ & $-0.91^{\mathrm{NS}}$ & $-1.2^{\mathrm{NS}}$ \\
$C C A L \times T$ & $0.01^{* *}$ & $-0.0002^{\mathrm{NS}}$ & $-0.03^{\mathrm{NS}}$ & $-0.08^{\mathrm{NS}}$ & $0.05^{\mathrm{NS}}$ & $0.02^{\mathrm{NS}}$ & $0.25^{\mathrm{NS}}$ & $-0.38^{\mathrm{NS}}$ \\
$C C A L \times C C A L$ & $0.02^{\mathrm{NS}}$ & $-0.003^{\mathrm{NS}}$ & $-0.04^{\mathrm{NS}}$ & $-0.02^{\mathrm{NS}}$ & $-0.42^{\mathrm{NS}}$ & $-0.28^{\mathrm{NS}}$ & $-0.23^{\mathrm{NS}}$ & $0.72^{\mathrm{NS}}$ \\
$\mathrm{R}^{2}$ & 0.84 & 0.92 & 0.93 & 0.72 & 0.95 & 0.91 & 0.21 & 0.88 \\
$F$ & $22^{* * *}$ & $50^{* * *}$ & $56^{* * *}$ & $11^{* * *}$ & $82^{* * *}$ & $40^{* * *}$ & $1.4^{\mathrm{NS}}$ & $38^{* * *}$ \\
\hline
\end{tabular}

${ }^{1} \mathrm{df}=11 ; \mathrm{n}=60 ; \mathrm{R}^{2}=$ determination coefficient; $F=$ ANOVA $F$-statistic; $T=$ temperature; $\beta=$ a constant as defined by the experimental design and used in Eq. [1] to establish the experimental cutting time; $C C A L=$ calcium chloride addition level; $\times$ denotes interaction of experimental factors.

${ }^{2} W F_{5}=$ whey fat content at 5 min after cutting; $W F_{85}=$ whey fat content at 85 min after cutting; WFL = total whey fat losses $(\mathrm{g})$ at the end of each experiment; $C M_{5}=$ curd moisture at 5 min after cutting; $C M_{85}=$ curd moisture at $85 \mathrm{~min}$ after cutting; $C Y_{\mathrm{wb}}=$ curd yield on a wet basis; $C Y_{\mathrm{db}}=$ curd yield on a dry basis; $C F R=$ curd fat retention;

$* * * P<0.001 ; * * P<0.01 ; * P<0.05 ; \mathrm{NS}=$ not significant.

\section{RESULTS}

\section{Effect of Temperature, $\mathrm{CaCl}_{2}$, and Cutting Time on Component Losses and Curd Yield}

The effect of independent variables on component losses and recoveries and curd yields was investigated using the RSREG procedure in SAS. The results of the ANOVA are shown in Table 4 for $W F_{5}, W F_{85}, W F L$, $C M_{5}, C M_{85}, C Y_{\mathrm{wb}}, C Y_{\mathrm{db}}$, and $C F R$ models. All of the models except $C Y_{\mathrm{db}}$ were highly significant in their fit $\left(\mathrm{R}^{2} \geq 0.72, P<0.001\right)$. Models $W F_{85}$ and $W F L$ were significantly affected by temperature and temperature-squared $(P<0.0001)$ as well as by the cutting time $(P=0.03)$ and temperature-cutting time interaction terms $(P=0.004)$. The results of the ANOVA for $W F_{15}$, $W F_{25}, W F_{35}, W F_{45}, W F_{55}, W F_{65}$, and $W F_{75}$ (not shown) were the same as for $W F_{85}$. For $W F_{5}, C C A L$ and the $C C A L$-temperature interaction terms were also significant $(P<0.006)$. This suggests that $C C A L$ will predominantly affect the concentration of fat in the whey in the early stages of syneresis. van den Bijgaart (1988) stated that adding calcium up to $4.5 \mathrm{mM}$ enhances the rate of aggregation but also leads to a faster increase in the rigidity of the network. Initially, increased aggregation leads to higher initial syneresis pressure, but the increase in pressure is hindered at an earlier stage due to reduced rearrangement. Therefore, the addition of calcium tended to increase the initial curd shrinkage rate. In the case of the $C M_{85}$ ANOVA model, no term except the intercept $(P<0.0001)$ was found to be significant. However, the temperature and temperature-squared term did significantly $(P<0.02)$ af- fect $C M_{5}$ (Table 4) and $C M_{15}, C M_{25}, C M_{35}, C M_{45}, C M_{55}$, and $C M_{65}$ (results not shown).

Both $C Y_{\text {wb }}$ and $C Y_{\mathrm{db}}$ were significantly affected by temperature $(P<0.01)$. The calcium chloride-cutting time interaction term was found to be significant for $C Y_{\text {wb }}(P<0.05)$. Temperature and cutting time were significant in determining the retention of fat in the curd with temperature, temperature-squared, and the temperature-cutting time interaction terms all found to be significant for $C F R(P<0.01)$.

The response surface graphs for WFL, $C M_{85}$, and $C Y_{\text {wb }}$ as a function of the independent variables are shown in Figure 1. The WFL was minimized between 28 and $30^{\circ} \mathrm{C}$ depending on $t_{\text {cut }}$ (Figures $1 \mathrm{a}$ and b). Figure $1 \mathrm{~b}$ graphically shows the significant interaction existing between $t_{\text {cut }}$ and temperature $(P<0.01$; Table 4). It shows that, at lower temperatures, decreasing $t_{\text {cut }}$ increased $W F L$, whereas at high temperatures, decreasing $t_{\text {cut }}$ decreased WFL. At an early $t_{\text {cut }}(\beta=1.8)$, the optimum temperature for minimizing $W F L$ was $30^{\circ} \mathrm{C}$, but at later $t_{\text {cut }}(\beta=3.7), W F L$ was minimized at $28^{\circ} \mathrm{C}$. Figure $1 \mathrm{c}$ confirms that increasing $\beta$ (i.e., $t_{\text {cut }}$ ) at $33^{\circ} \mathrm{C}$ increased $W F L$. This finding may have practical implications for cheese processing. It suggests that delaying cutting time at this typical cheese-making temperature would tend to increase fat losses. Figure $1 \mathrm{c}$ also indicates that there may be an interactive effect between $C C A L$ and $t_{\text {cut }}$ on $W F L$ at $33^{\circ} \mathrm{C}$. At early $t_{\text {cut }}$, increasing $C C A L$ decreased fat losses whereas the opposite effect was observed at late $t_{\text {cut }}$.

Figure $1 \mathrm{~d}$ and $1 \mathrm{e}$ show the effect of temperature on $C M_{85}$ although this effect was not found to be signifi- 

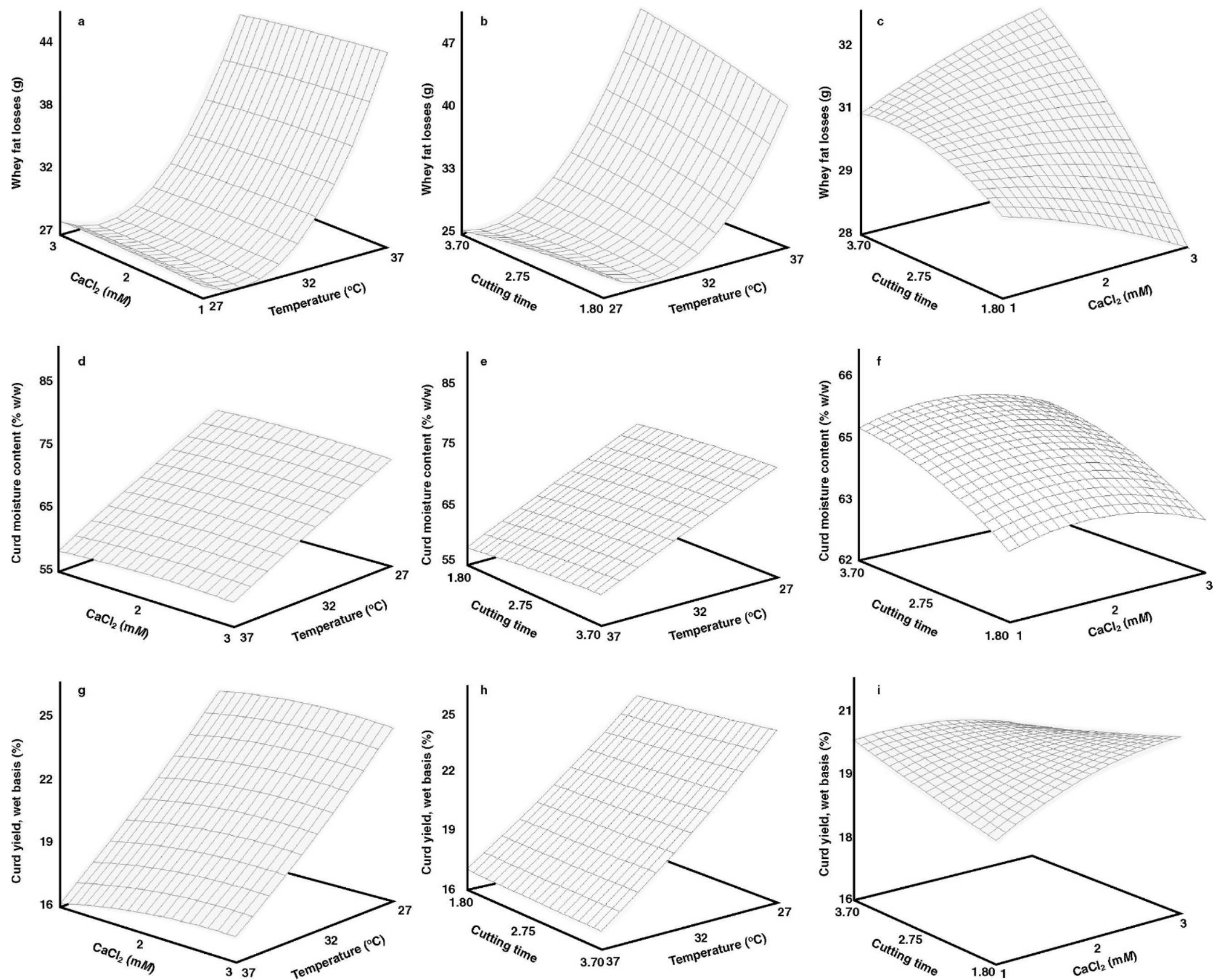

Figure 1. Response surface plots for the effect of independent variables $\mathrm{CaCl}_{2}$ addition level, temperature, and cutting time on total whey fat losses (a, b, c), curd moisture content at 85 min after cutting (d, e, f), and curd yield on a wet basis $(\mathrm{g}, \mathrm{h}, \mathrm{i})$ 
cant $(P=0.07)$. Decreasing temperature was shown to increase $C M_{85}$. In Figure 1e and 1f, increasing $t_{\text {cut }}$ was found to increase $C M_{85}$. The $C C A L$ was observed to have a limited effect on $C M_{85}$ at $33^{\circ} \mathrm{C}$ (Figure 1f) with $C M_{85}$ maximized at $\sim 1.8 \mathrm{~m} M$.

The effect of temperature on $C Y_{\text {wb }}$ is shown in Figures $1 \mathrm{~g}$ and $1 \mathrm{~h}$. Decreasing the temperature was shown to increase $C Y_{\mathrm{wb}}$; this is related to the reduced extent of syneresis. The significant interactive effect $(P<0.05$; Table 4$)$ of $C C A L$ and $t_{\text {cut }}$ on $C Y_{\text {wb }}$ is shown in panel $\mathrm{i}$ of Figure 1. At low $C C A L$, increasing $t_{\text {cut }}$ increased $C Y_{\mathrm{wb}}$, whereas at high $C C A L$, increasing $t_{\text {cut }}$ reduced $C Y_{\mathrm{wb}}$. The effect of $t_{\text {cut }}$ also differed depending on the $C C A L$. At earlier $t_{\text {cut }}$, increasing the $C C A L$ increased $C Y_{\mathrm{wb}}$; the opposite effect was observed in latercut gels.

Figure 2 shows the response surface graphs for $C Y_{\mathrm{db}}$ and $C F R$ as a function of the independent variables. The effect of temperature on $C Y_{\mathrm{db}}$ can be seen in Figures $2 \mathrm{a}$ and b. The $C Y_{\mathrm{db}}$ was maximized at $33^{\circ} \mathrm{C}$ for low $C C A L$ (1 to $1.2 \mathrm{mM}$ ) and at $34^{\circ} \mathrm{C}$ for higher $C C A L$ (1.3 to $3 \mathrm{mM}$ ) in Figure $2 \mathrm{a}$ and maximized at $35^{\circ} \mathrm{C}$ (Figure $2 \mathrm{~b}$ ) for early $t_{\text {cut }}\left(\beta=1.8\right.$ to 2 ) and $33^{\circ} \mathrm{C}$ at later $t_{\text {cut }}(\beta=3$ to 3.7). Therefore, as was observed for WFL (Figure $1 \mathrm{~b}$ ), varying $t_{\text {cut }}$ shifted the temperature at which the maximum level of TS was retained, with the maximum $C Y_{\mathrm{db}}$ occurring at a higher temperature $\left(35^{\circ} \mathrm{C}\right)$ when $t_{\text {cut }}$ was earlier (Figure $2 \mathrm{~b}$ ).

The results obtained for $C F R$ also support the results observed for $W F_{85}$ (Figure 1a, b, and c). The $C F R$ was maximized in the temperature range 29 to $31^{\circ} \mathrm{C}$ (Figures $2 \mathrm{~d}$ and e), with the levels of CFR decreasing rapidly with increasing temperature (Figure $2 \mathrm{~d}$ and e). Terms $C C A L$ and $t_{\text {cut }}$ also affected the fat retention capacity of curd particles. The effect of high CCAL and later $t_{\text {cut }}$ resulted in curd particles that had a reduced ability to retain fat (Figure $2 \mathrm{f}$ ).

\section{Effect of Temperature, $\mathrm{CaCl}_{2}$, and Cutting Time on the LFV Light Backscatter Parameters}

The effect of independent variables on light backscatter parameters derived from the LFV signal was also investigated using the RSREG procedure in SAS. The results of the ANOVA are shown in Table 5. The fit for the $t_{\max }, t_{2 \max }$, and $t_{2 \min }$ models were higher $\left(\mathrm{R}^{2}\right.$ $\geq 0.88, P<0.001)$, than for the $\Delta R_{\text {syn }}$ model $\left(\mathrm{R}^{2}=0.68\right.$, $P<0.001)$. The effect of $t_{\text {cut }}$ on $t_{\max }, t_{2 \max }$, and $t_{2 \min }$ was not included in Table 5 because these parameters were determined during milk coagulation, before cutting the gel. As expected, $t_{\max }, t_{2 \max }$, and $t_{2 \min }$ were strongly affected by temperature and the temperature-squared term $(P<0.001)$, due to the higher rate of enzymatic hydrolysis of $\kappa$-casein (O'Callaghan et al., 2001) and the casein micelle network assembly (Castillo et al., 2006a). Time parameters $t_{2 \max }$ and $t_{2 \min }$ were significantly affected by the temperature-CCAL interaction term $(P<0.03)$. The $C C A L$ has previously been shown to have a direct effect on aggregation and firming rates (Castillo et al., 2002). The percentage decrease in $R$ during syneresis $\left(\Delta R_{\mathrm{syn}}\right)$ was significantly affected by temperature, the temperature-squared term, cutting time, and the cutting time-squared term.

The response surface graphs for $t_{\max }, t_{2 \max }, t_{2 \min }$, and $\Delta R_{\text {syn }}$ as a function of the independent variables are shown in Figure 3. As expected, the response surface graphs for $t_{\max }, t_{2 \max }$, and $t_{2 \min }$ (Figure $3 \mathrm{a}, \mathrm{b}, \mathrm{c}$ ) were very similar. In all cases, because of the effect of temperature on enzymatic hydrolysis and casein micelle aggregation, decreasing temperature increased each of the time parameters. This is in agreement with the results of Castillo et al. (2006a), who claimed that time parameters $t_{\max }, t_{2 \max }$, and $t_{2 \min }$ decreased with increasing temperature. It is also observed in Figure $3 \mathrm{a}, \mathrm{b}$, and $\mathrm{c}$ that the response of time parameters to temperature was not entirely linear, with the rate of change in these parameters decreasing with increasing temperature.

The effect of $C C A L$ on all time parameters was consistent. Although $C C A L$ had a limited effect at high temperature, increasing $C C A L$ decreased $t_{\max }, t_{2 \min }$, and $t_{2 \max }$ at low temperatures due to faster aggregation and curd firming rates. This is in agreement with results presented by Castillo et al. (2002) and Najera et al. (2003). This may be due to the large effect that temperature has on aggregation, masking the effect of $C C A L$ at high temperatures.

In the response surface graphs for $\Delta R_{\text {syn }}$ (Figure $3 \mathrm{~d}$, $\mathrm{e}$, and f), temperature and $t_{\text {cut }}$ maximized $\Delta R_{\text {syn }}$ from 31 to $32^{\circ} \mathrm{C}$ and from 2.6 to 1.8 (i.e., $\beta=2.6$ to 1.8 ), respectively. It was also noted that at high $C C A L$ (3 $\mathrm{m} M)$, the maximum $\Delta R_{\text {syn }}$ occurred at the shortest $t_{\text {cut }}$ $(\beta=1.8)$.

\section{DISCUSSION}

\section{Rheological and Microstructural Properties of Milk Gels at Cutting}

It can be concluded from the current results that there is an optimum gel firmness at which the gel should be cut to achieve maximum retention of fat as well as an optimum curd moisture content that will maximize product yield and quality. The development of gel firmness and network rearrangement during the aging of casein gels before cutting, and the complex interactions existing among firmness, rearrangement capability, and processing factors such as gelation temperature, $\mathrm{CaCl}_{2}$ addition, and cutting time can be 

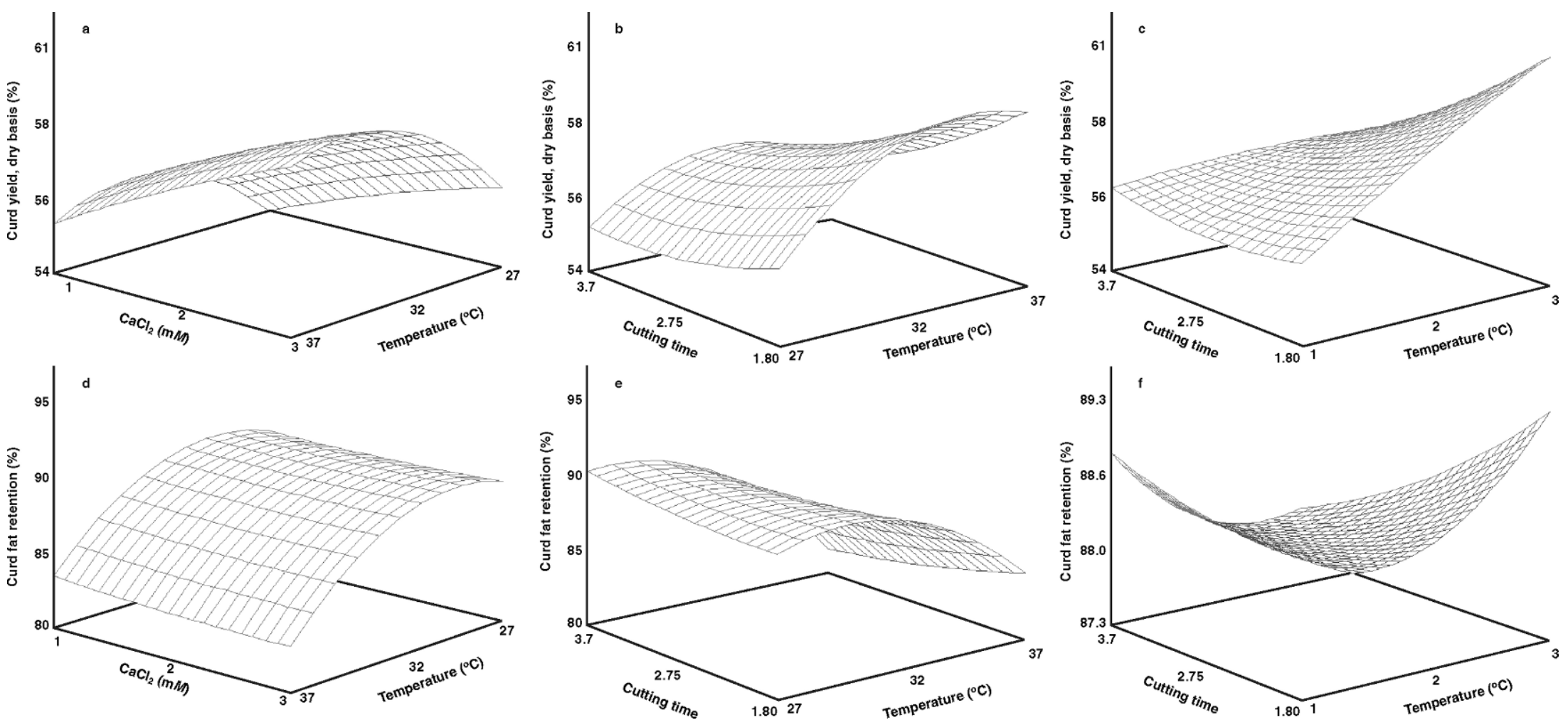

Figure 2. Response surface plots for the effect of independent variables $\mathrm{CaCl}_{2}$ addition level, temperature, and cutting time on curd yield on a dry basis (a, b, c) and curd fat retention $(\mathrm{d}, \mathrm{e}, \mathrm{f})$ 
Table 5. Analysis of variance ${ }^{1}$ and $F$-statistic for the light backscatter parameters

\begin{tabular}{lcccc}
\hline & \multicolumn{3}{c}{ Light backscatter parameters ${ }^{2}$} \\
\cline { 2 - 5 } Factor & $t_{\max }$ & $t_{2 \max }$ & $t_{2 \min }$ & $\Delta R_{\mathrm{syn}}$ \\
\hline$T$ & $-3.2^{* * *}$ & $-2.1^{* * *}$ & $-4.3^{* * *}$ & $20^{* * *}$ \\
Cutting time $(\beta)$ & $\mathrm{NA}$ & $\mathrm{NA}$ & $\mathrm{NA}$ & $28^{*}$ \\
$C C A L$ & $-0.87^{\mathrm{NS}}$ & $-2.1^{\mathrm{NS}}$ & $-1.6^{\mathrm{NS}}$ & $2.7^{\mathrm{NS}}$ \\
$\beta \times \beta$ & $\mathrm{NA}$ & $\mathrm{NA}$ & $\mathrm{NA}$ & $-3.38^{*}$ \\
$\beta \times T$ & $\mathrm{NA}$ & $\mathrm{NA}$ & $\mathrm{NA}$ & $-0.30^{\mathrm{NS}}$ \\
$T \times T$ & $0.04^{* * *}$ & $0.02^{* * *}$ & $0.058^{* * *}$ & $-0.31^{* * *}$ \\
$C C A L \times \beta$ & $\mathrm{NA}$ & $\mathrm{NA}$ & $\mathrm{NA}$ & $-1.25^{\mathrm{NS}}$ \\
$C C A L \times T$ & $0.07^{\mathrm{NS}}$ & $0.09^{*}$ & $0.10^{*}$ & $0.08^{\mathrm{NS}}$ \\
$C C A L \times C C A L$ & $-0.15^{\mathrm{NS}}$ & $-0.88^{\mathrm{NS}}$ & $-0.16^{\mathrm{NS}}$ & $-0.98^{\mathrm{NS}}$ \\
$\mathrm{R}^{2}$ & 0.90 & 0.88 & 0.89 & 0.68 \\
$F$ & $41^{* * *}$ & $30^{* * *}$ & $33^{* * *}$ & $9.4^{* * *}$ \\
\hline
\end{tabular}

${ }^{1} \mathrm{df}=11 ; \mathrm{n}=60 ; \mathrm{R}^{2}=$ determination coefficient; $F=$ ANOVA $F$ statistic; $T=$ temperature; $\beta=$ a constant as defined by the experimental design and used in Eq. [1] to establish the experimental cutting time; $C C A L=$ calcium chloride addition level; $\times$ denotes interaction of experimental factors.

${ }^{2} t_{\max }=$ time to the first maximum of $R^{\prime} ; t_{2 \max }=$ time to the first maximum of $R^{\prime \prime} ; t_{2 \min }=$ time to the first minimum of $R^{\prime \prime} ; \Delta R_{\mathrm{syn}}=$ percentage decrease in $R$ from $t_{s(0)}$ to $t_{s(85)} ; \mathrm{NA}=$ not applicable.

$* * * P<0.001 ; * P<0.05 ; \mathrm{NS}=$ not significant.

used to explain a number of mechanisms that lead to the results observed in Figures 1, 2, and 3. However, before addressing the analysis of the results of this study, a short review of the relationships among parameters such as temperature and aging time and rheological and microstructural properties of rennet induced milk gels is warranted.

It is known that the storage modulus $\left(\mathbf{G}^{\prime}\right)$ of the gel will increase after gelation until (if left for a long enough period) it reaches a plateau; that is, ultimate firmness (Zoon et al., 1988; Dejmek and Walstra, 2004). Under certain circumstances, if the gel is not cut, $\mathrm{G}^{\prime}$ may then subsequently decrease (Zoon et al., 1988) due to microsyneresis, which occurs when regions of the gel become dense and whey is forced into pores that grow in diameter. Although the development of $\mathrm{G}^{\prime}$ with time is clear, there is some disagreement regarding the effect of temperature on curd firmness. Several authors have found that the rate of network formation is temperature dependent. Sharma et al. (1993) found that aggregation rate and curd firmness increased with increasing temperature. Although there is consensus among authors regarding the effect of temperature on both aggregation and curd firming rate constants, there is some disagreement regarding the effect of temperature on ultimate firmness. Some authors have stated that the final rigidity of rennet-induced milk gels increases with temperature (Bohlin et al., 1984), whereas others found that the maximum firmness of milk gels decreases with increasing temperature (Zoon et al., 1988). This is due to $G^{\prime}$ being dependent not only on temperature, but also on time. If the $\mathrm{G}^{\prime}$ value of the milk gels is recorded after the gels have reached ultimate firmness (i.e., they have reached a plateau), then it is clear that the firmness of the gels will decrease with increasing temperature (Zoon et al., 1988). Therefore, while G' initially increases more rapidly at higher temperatures, it will reach a maximum value more quickly and that value will be smaller than at lower temperatures (Zoon et al., 1988). This was also observed by Lagoueyte et al. (1994) who found that ultimate maximum firmness decreased with increasing temperature, but at aging times less than $4 \mathrm{~h}$, the opposite was found to be true. This finding was further confirmed by Mellema et al. (2002), who stated that as long as the gel was in the early stages of aging, $\mathrm{G}^{\prime}$ is larger at higher temperatures. This occurred for the experimental conditions in this study, where the gel was cut within a time range of 9 to $48 \mathrm{~min}$ from enzyme addition.

Zoon et al. (1988) also found that at higher temperatures the rate of change in permeability with time is greater, the maximum endogenous syneresis pressure is reached more quickly after rennet addition, and the maximum endogenous syneresis pressure increased with increasing temperature. These factors were said to result from a rapid coarsening of the network. Coarsening results from the spontaneous breaking and rearranging of the network. As strands rearrange they form new strands and clusters that become denser and thicker, resulting in a more open network with larger pores and, hence, greater permeability (Lagoueyte et al., 1994). It has been widely observed that this change in permeability over time occurs more quickly in gels formed at higher temperatures, which will also have a greater final permeability (van den Bijgaart, 1988; Lagoueyte et al., 1994). This is due to the shorter half-life of the bonds formed at higher temperatures. The shorter half-life means that breaking of bonds and disruption of junctions occurs more easily. van den Bijgaart (1988) suggested that this indicated a more rapid decrease in the number of stress-containing junctions at higher temperatures, which could be interpreted as a relatively quick change to junctions with a high number of bonds. During aging, this rearrangement (which leads to denser aggregates and larger pores) can lead to tensile stress in nearby strands. Therefore, strands will be stretched and become thinner. Over a long aging time, this can cause strands to break, which forces whey out of specific regions of the gel that became denser, and into the growing pores. This is termed microsyneresis and it may result in a decrease in gel firmness. 

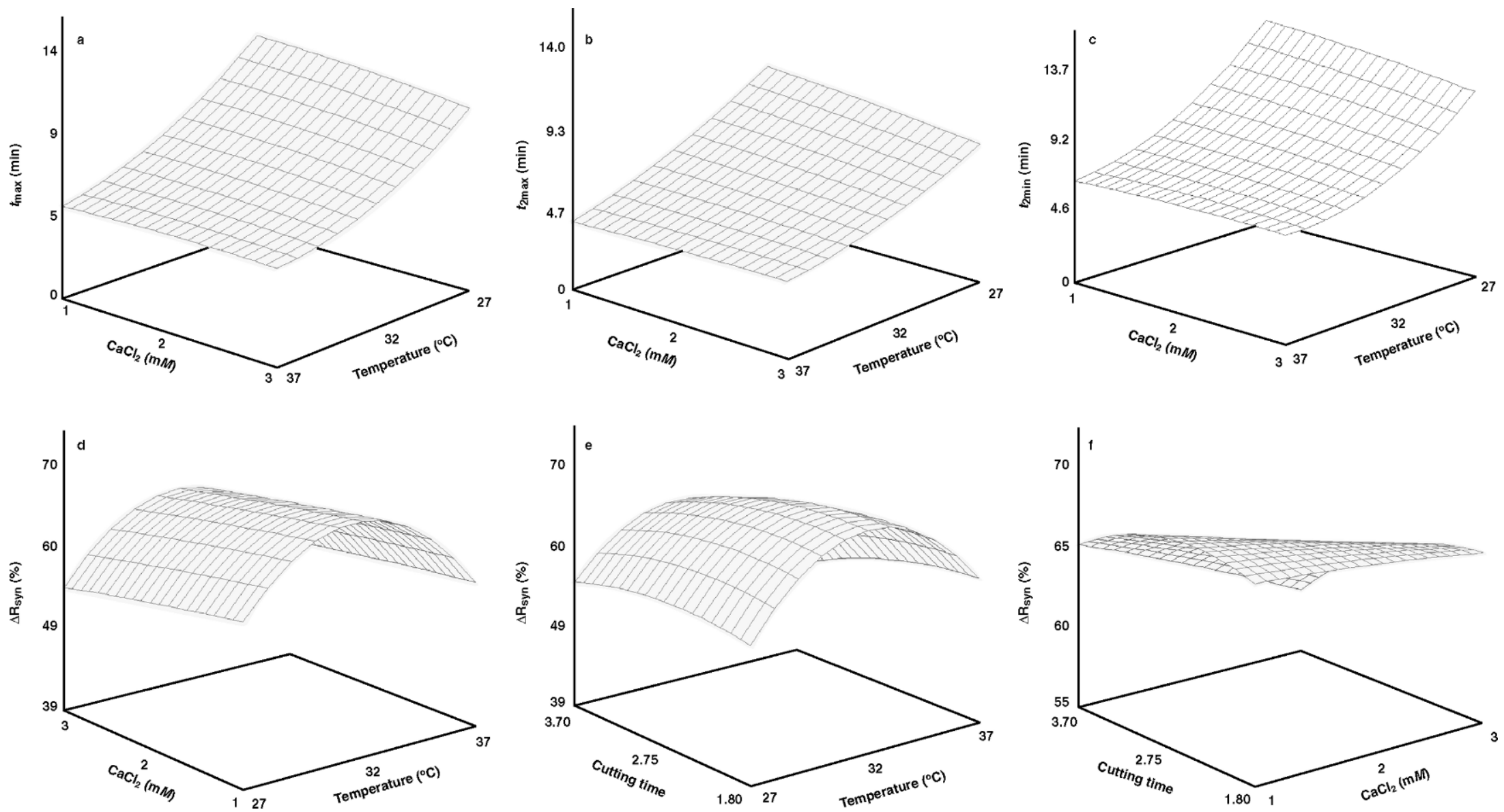

Figure 3. Response surface plots for the effect of independent variables $\mathrm{CaCl}_{2}$ addition level, temperature, and cutting time on optical parameters derived from the large field of view light backscatter sensor: $t_{\max }$ (a), $t_{2 \max }$ (b), $t_{2 \min }$ (c) and $\Delta R_{\mathrm{syn}}\left(\mathrm{d}\right.$, e, f), where $t_{\max }=$ time to the first maximum of $R^{\prime} ; t_{2 \max }=$ time to the first maximum of $R^{\prime \prime}$; $t_{2 \min }=$ time to the first minimum of $R^{\prime \prime}$; and $\Delta R_{\mathrm{syn}}=$ percentage decrease in $R$ from $t_{s(0)}$ to $t_{s(85)}$. 


\section{Optimizing Curd Firmness at Cutting Affects Curd Moisture and Fat Losses}

The result of not optimizing firmness on fat losses was seen in Figure 1a, b, and c for WFL and in Figure $2 \mathrm{~d}$, e, and f for $C F R$. As expected, the response surface graphs for WFL and CFR displayed a similar trend. The WFL and CFR were minimized and maximized, respectively, between 28 and $35^{\circ} \mathrm{C}$, because this was the temperature range at which a gel with optimum firmness was formed over the range of $t_{\text {cut }}$ and $C C A L$ investigated. Our data shows, as suggested by Johnson et al. (2001), that the retention of fat is dependent on relative rigidity and structure of the network at cutting. At temperatures below $28^{\circ} \mathrm{C}$, the gel will not have reached its ultimate firmness (i.e., plateau in $\mathrm{G}^{\prime}$ ) before cutting. Therefore, increasing the temperature increased the rate of curd firming and a firmer gel was formed as the temperature reached $35^{\circ} \mathrm{C}$. At temperatures below $28^{\circ} \mathrm{C}$, the gel was fragile when cut, which results in high levels of curd fines and fat losses. As the temperature increases, curd firmness at cutting reaches an optimum and fat losses are minimized. Above $35^{\circ} \mathrm{C}$, the network becomes more rigid, rapid coarsening occurs, and the gel has a greater porosity, all of which assist the release of fat. Indeed, because the average melting point of milk fat is $37^{\circ} \mathrm{C}$ (Fox and McSweeney, 2006), fat has much greater mobility at higher temperatures approaching $37^{\circ} \mathrm{C}$, which results in even greater levels of fat being released.

This effect of firmness also explains the interactive effect of temperature and $t_{\text {cut }}$ on WFL and CFR (Figures $1 \mathrm{~b}$ and $2 \mathrm{e})$. At lower temperatures $\left(<28^{\circ} \mathrm{C}\right)$ the gel will be relatively weak when cut. Therefore, increasing $t_{\text {cut }}$ at temperatures up to $28^{\circ} \mathrm{C}$ results in a firmer gel with a better fat retention capacity. Consequently, increasing $t_{\text {cut }}$ at low temperatures decreased WFL (Figure 1b). However, at higher temperature $\left(>30^{\circ} \mathrm{C}\right)$, coarsening of the milk gel occurs more rapidly, permeability of the gel is greater, and microsyneresis can occur at longer aging times. All of these factors reduce the ability of the curd to retain fat. In this case, increasing $t_{\text {cut }}$ will only exacerbate these processes; hence, at temperatures $>30^{\circ} \mathrm{C}$, increasing $t_{\text {cut }}$ resulted in greater WFL.

The importance of combining the correct $t_{\text {cut }}$ and $C C A L$ to maximize fat retention is seen in Figures 1c and $2 \mathrm{f}$. These figures represent the effect of $t_{\text {cut }}$ and $C C A L$ on fat losses at a constant temperature of $33^{\circ} \mathrm{C}$. We observed that, at $33^{\circ} \mathrm{C}$, the gel would have reached a suitable firmness. Consequently, the highest WFL and lowest $C F R$ occurred at the longest $t_{\text {cut }}(\beta=3.7)$ and highest CCAL (3 $\mathrm{mM}$; Figures 1c and 2f), all of which contributed to exceed the optimum firmness of the gel, which would result in microsyneresis, increased porosity, and greater fat losses.

Increasing temperature decreased $C M_{85}$ (Figure 1d and e) because gels formed at higher temperatures have increased rearrangement capability (larger tan $\delta$ ) and greater permeability, which results in a faster rate of syneresis and a larger amount of whey separation (Castillo et al., 2006b). The effect of increasing $t_{\text {cut }}$ on increasing $C M_{85}$ (Figure $1 \mathrm{e}$ and $\mathrm{f}$ ) is in agreement with a number of previous studies (Johnson et al., 2001). This can be attributed to the firmer gels having a reduced capacity to rearrange and shrink, and thus a reduced ability to expel whey. The $C C A L$ was observed to have a small effect on $C M_{85}$ (Figure 1f) with $C M_{85}$ maximized at $\sim 1.8 \mathrm{mM}$. van den Bijgaart (1988) also found that $C C A L$, with correction for $\mathrm{pH}$ changes, had a limited effect on the syneresis rate. Calcium addition enhances aggregation and produces a higher initial syneresis pressure; however, the addition of calcium will also lead to a more rapid increase in the rigidity of the curd, and hence, a decrease in rearrangement and a decrease in syneresis (van den Bijgaart, 1988), which may explain the initial increase in $C M_{85}$ with increasing $C C A L$ (1 to $1.8 \mathrm{mM}$; Figure 1f). Although van den Bijgaart (1988) found that gel permeability was not affected by $C C A L$, he stated that this was somewhat surprising because the addition of calcium chloride increases the amount of calcium bound to the micelles, which, in turn, decreases their voluminosity. A decrease in the size of the gel building blocks may be expected to increase gel permeability, therefore increasing syneresis, which may account for the decrease in $C M_{85}$ at $C C A L>1.8 \mathrm{mM}$ (Figure 1f).

\section{Retaining Adequate Moisture and TS to Maximize Curd Yield and Quality}

Lawrence et al. (1993) stated that cheese yield cannot be considered in isolation, but only in relation to the overall quality of the cheese. Although increasing the moisture content of cheese will increase the yield, unless it is associated with a greater retention of casein and fat, it may result in a decrease of quality through greater water activity, which will affect the ripening process, microbiological quality, and the development of flavor and texture. Therefore, to maximize cheese yield and quality, the retention of moisture and TS must be optimized.

Decreasing temperature increased $C Y_{\text {wb }}$ (Figure $1 \mathrm{~g}$ and $\mathrm{h}$ ) due to the reduced extent of syneresis resulting in higher curd moisture contents (Figure 1d and e). However, $C Y_{\mathrm{db}}$ tended to be maximized between 33 and $35^{\circ} \mathrm{C}$ depending on $C C A L$ and $t_{\text {cut }}$ (Figures $2 \mathrm{a}$ and b) because gels below this temperature range would 
tend to be weak and produce a fine curd when cut resulting in higher levels of fat and fines losses. However, at higher temperatures we noted much higher levels of fat losses (Figure 1a), which decreased $C Y_{\mathrm{db}}$ (Figure 2a). The significant interactive effect of $C C A L$ and $t_{\text {cut }}$ on $C Y_{\text {wb }}(P<0.05$; Table 4 and Figure 1i) may be explained through the retention of casein and TS as well as moisture. This figure (Figure 1i) is representative of the effect of $C C A L$ and $t_{\text {cut }}$ on $C Y_{\text {wb }}$ at $33^{\circ} \mathrm{C}$. Therefore, the weakest gel in this figure is formed at the lowest $C C A L(1 \mathrm{mM})$ and $t_{\text {cut }}(\beta=1.8)$ levels, which results in higher losses of casein, fines, and fat (Figure 2c), as well as a low moisture content (Figure 1f), and hence the lowest $C Y_{\mathrm{wb}}$. This is confirmed in Figure 2c, in which a low $C Y_{\mathrm{db}}$ (low retention of TS) is observed at the lowest $C C A L$ and $t_{\text {cut }}$. In fact, it would seem that there is a range of $C C A L$ and $t_{\text {cut }}$ levels across which $C Y_{\mathrm{wb}}$ is maximized (Figure 1i). This is observed as $C Y_{\text {wb }}$ maximized diagonally across Figure 1i from $t_{\text {cut }}=3.7$ and $C C A L=1 \mathrm{~m} M$ to $t_{\text {cut }}=1.8$ and $C C A L=$ $3 \mathrm{~m} M$. Increasing $C C A L$ at early $t_{\text {cut }}$ (1.8) increased curd yield (Figures $1 \mathrm{i}$ and $2 \mathrm{c}$ ) through a combination of TS and moisture retention. This suggests that $C C A L$ is compensating for the slightly less firm gel at low $t_{\text {cut }}$ by increasing the firmness of the gel; hence, there is greater retention of TS; that is, $C Y_{\mathrm{db}}$ (Figure 2c) including fat (Figure 1c). It should also be noted that $C Y_{\text {wb }}$ increases rapidly at short $t_{\text {cut }}(1.8)$ when $C C A L$ is increased from 1 to $2 \mathrm{mM}$ but this increase slows as $C C A L$ increases from 2 to $3 \mathrm{mM}$ (Figure 2i). Although both TS (Figure 1c and 2c) and moisture (Figure 1f) are retained when $C C A L$ increases from 1 to $2 \mathrm{mM}$, curd moisture will begin to decrease again if additional $\mathrm{CaCl}_{2}$ is added (Figure 2f); hence, $C Y_{\mathrm{wb}}$, at short $t_{\text {cut }}(1.8)$, starts to level off when $C C A L$ increases to $3 \mathrm{mM}$ (Figure 2i). Increasing $t_{\text {cut }}$ at low $C C A L$ levels has a compensatory effect on $C Y_{\text {wb }}$ mainly through retention of moisture. We have observed that, at $33^{\circ} \mathrm{C}$, increasing $C C A L$ increased $C M_{85}$ (Figure 1f; from 1 to $2 \mathrm{mM}$ ) but also increased WFL (Figure 1c). At low $C C A L$, increasing $t_{\text {cut }}$ had a minimal effect on overall $C Y_{\mathrm{db}}$ (Figure 2c). Therefore, the observed increase in $C Y_{\text {wb }}$ when $t_{\text {cut }}$ is lengthened at low $C C A L$ (Figure 1i) can be attributed to an undesirable increase in curd yield; that is, increased moisture retention without an increase in TS retention. We noted that the highest $W F L$ occurred at the longest $t_{\text {cut }}$ (3.7) and highest CCAL (3 mM; Figure 1c). This was also observed in the lower $C Y_{\mathrm{db}}$ obtained under the same conditions in Figure 2c. By employing these conditions $(C C A L=$ $3 \mathrm{~m} M$ and $t_{\text {cut }}=3.7$ at $33^{\circ} \mathrm{C}$ ), the firmness and rigidity of the gel is maximized and rapid coarsening and microsyneresis can occur, which results in higher WFL reducing the $C Y_{\mathrm{db}}$ (Figure 2c) and affecting $C Y_{\mathrm{wb}}$ (Figure 1i).

These results indicate that within an optimal temperature range, possibly 28 to $35^{\circ} \mathrm{C}$, a shorter $t_{\text {cut }}$ and higher $C C A L$ will maximize the retention of TS, casein, and fat, but reduce curd moisture content, whereas a later $t_{\text {cut }}$ and lower $C C A L$ will lower retention of TS but increase curd moisture. Therefore, to maximize both curd yield and quality it is necessary to select a combination of conditions that will maximize firmness while avoiding microsyneresis.

\section{Relationship Between Light Backscatter Signal from the LFV and Syneresis}

Increasing temperature decreased the coagulation time parameters, $t_{\max }, t_{2 \max }$, and $t_{2 \min }$ (Figure $3 \mathrm{a}, \mathrm{b}, \mathrm{c}$ ). This is due to the effect that temperature has on both the primary (enzymatic hydrolysis) and secondary (aggregation reaction) phases of coagulation (Castillo et al., 2003). The decrease in the rate of change in these parameters with increasing temperature is in agreement with previously reported results. Castillo et al. (2003) stated that many authors, including Zoon et al. (1988), found a nonlinear effect of temperature on clotting time. This nonlinear effect may be related to the higher temperature coefficient $\left(\boldsymbol{Q}_{\mathbf{1 0}}\right)$ values for coagulation between 20 and $30^{\circ} \mathrm{C}$ than between 30 and $40^{\circ} \mathrm{C}$. Castillo et al. (2003) suggested that this nonlinear effect might be due to heat inactivation of chymosin with increasing temperature. The $Q_{10}$ value for coagulation may also explain the greater observed affect of $C C A L$ on time parameters at low temperatures rather than at high temperatures (Figure $3 \mathrm{a}, \mathrm{b}$, c). It is known that although temperature will affect both phases of coagulation, the $Q_{10}$ values for aggregation (11 to 30) are much higher than those reported for enzymatic hydrolysis (1.3 to 2 ), indicating that aggregation is more sensitive to changes in temperature than enzymatic hydrolysis (Castillo et al., 2000). In this study, because $\mathrm{pH}$ was adjusted following $\mathrm{CaCl}_{2}$ addition, the observed effect of $C C A L$ was due to the effect of $\mathrm{CaCl}_{2}$ on aggregation. This suggests that the large effect of temperature on aggregation at high temperatures (large $Q_{10}$ value) was masking the smaller effect that $C C A L$ would have on aggregation kinetics; it was only at low temperatures that the effect of $C C A L$ becomes apparent.

Fagan et al. (2007) found that the LFV sensor response during syneresis is correlated to changes in curd moisture and whey fat content. The response surface graphs confirm those findings for $\Delta R_{\text {syn }}$ because they indicate that $\Delta R_{\text {syn }}$ tends to be small when there are high fat losses or the extent of whey release is low. 
For example, $\Delta R_{\text {syn }}$ as a function of temperature was maximized at approximately $30^{\circ} \mathrm{C}$ (Figure $3 \mathrm{~d}$ and e), which was within the temperature range at which WFL was minimized (Figure 1a and b). The decrease in $\triangle R_{\text {syn }}$ with increasing $C C A L$ may be explained as the effect of increased TS retention on $C Y_{\mathrm{db}}$ (Figure $2 \mathrm{a}$ ). The effect of $t_{\text {cut }}$ on $\Delta R_{\text {syn }}$ (Figure $3 \mathrm{~b}$ ) seems to be represented by the effect of $t_{\text {cut }}$ on $C Y_{\mathrm{db}}$ (Figure 2b), because at low temperatures $\left(27^{\circ} \mathrm{C}\right), C Y_{\mathrm{db}}$ was minimized at approximately a $t_{\text {cut }}$ of 2.6 , whereas $\Delta R_{\text {syn }}$ was maximized at a $t_{\text {cut }}$ of $\sim 2.6$. In Figure $3 f$, the lowest value of $\Delta R_{\text {syn }}$ corresponded with long $t_{\text {cut }}$ and high $C C A L$ (3.7 and $3 \mathrm{mM}$ ) at $33^{\circ} \mathrm{C}$. This suggests the gel was too firm when cut, and allowed rapid coarsening and microsyneresis to occur, ultimately resulting in the highest WFL (Figure 1c). High CCAL $(3 \mathrm{mM})$ and short $t_{\text {cut }}$ (1.8) tended to maximize $\Delta R_{\text {syn }}$ (Figure 3f), which was also attributed to the high retention of TS and fat (Figure 2c and f). These results suggest that the LFV sensor was sensitive to changes in moisture and TS retention, particularly fat.

\section{CONCLUSIONS}

The effects of temperature, calcium chloride addition level, and cutting time on curd moisture content, whey fat losses, and curd yield were examined. These results support the existence of an optimum level of curd firmness at cutting. The WFL was predominantly affected by temperature and $t_{\text {cut }}$. Temperature was also found to affect the rate of syneresis. Temperature, $C C A L$, and $t_{\text {cut }}$ significantly affected curd yield. It was concluded that there is an optimum firmness at which the gel should be cut to achieve maximum retention of fat as well as an optimum curd moisture content that will maximize product yield and quality. The $C F R$ and $C Y_{\mathrm{db}}$ were maximized in the temperature range 29 to $35^{\circ} \mathrm{C}$ depending on the $C C A L$ and $\mathrm{t}_{\text {cut }}$ used. Below this temperature range, the gel was fragile when cut, which can result in a fine curd and high fat loss. Above this temperature range, the network becomes more rigid, rapid coarsening occurs, and the gel has greater porosity, all of which assist in the release of fat. It was concluded that within an optimal temperature range, possibly 28 to $35^{\circ} \mathrm{C}$, a shorter $t_{\text {cut }}$ and higher $C C A L$ will maximize the retention of TS, casein, and fat, but reduce curd moisture content. A longer $t_{\text {cut }}$ and lower $C C A L$ will lower retention of TS but increase curd moisture. Therefore, to maximize curd yield and quality it is necessary to maximize firmness while avoiding microsyneresis. Optical parameters derived from the light backscatter profile of the LFV sensor during coagulation were found to be a function of temperature and $C C A L$, whereas the parameters generated from the
LFV sensor profile during syneresis were found to be a function of temperature and $t_{\text {cut }}$. These results contribute to the optimization of the cheese-making process and confirm the great potential of a light backscatter sensor with a large field of view as an online sensor technology that could provide comprehensive control of the cheese-making process within the vat.

\section{ACKNOWLEDGMENTS}

Funding for this research was provided by the Irish Department of Agriculture \& Food through the Food Institutional Research Measure (FIRM), by the Kentucky Science and Engineering Foundation (Project KSEF-407-RDE-004), and by the US Department of Agriculture (Project NRI-USDA 2005-35503-15390).

\section{REFERENCES}

Bohlin, L., P. O. Hegg, and H. Ljusbergwahren. 1984. Viscoelastic properties of coagulating milk. J. Dairy Sci. 67:729-734.

Castillo, M., J. A. Lucey, and F. A. Payne. 2006a. The effect of temperature and inoculum concentration on rheological and light scatter properties of milk coagulated by a combination of bacterial fermentation and chymosin. Cottage cheese-type gels. Int. Dairy J. 16:131-146.

Castillo, M., J. A. Lucey, T. Wang, and F. A. Payne. 2006b. Effect of temperature and inoculum concentration on gel microstructure, permeability and syneresis kinetics. Cottage cheese-type gels. Int. Dairy J. 16:153-163.

Castillo, M., F. A. Payne, C. L. Hicks, J. Laencina, and M. B. López. 2003. Effect of protein and temperature on cutting time prediction in goats' milk using an optical reflectance sensor. J. Dairy Res. 70:205-215.

Castillo, M., F. A. Payne, C. L. Hicks, J. Laencina, and M. B. López. 2002. Effect of calcium and enzyme in cutting time prediction of coagulating goats' milk using a light scattering sensor. Int. Dairy J. 12:1019-1023.

Castillo, M., F. A. Payne, C. L. Hicks, and M. B. López. 2000. Predicting cutting and clotting time of coagulating goat's milk using diffuse reflectance: Effect of $\mathrm{pH}$, temperature and enzyme concentration. Int. Dairy J. 10:551-562.

Castillo, M., F. Payne, and A. Shea. 2005. Development of a combined sensor technology for monitoring coagulation and syneresis operations in cheese making. J. Dairy Sci. 88(Suppl. 1):142. (Abstr.)

Dejmek, P., and P. Walstra. 2004. The syneresis of rennet-coagulated curd. Pages 70-103 in Cheese: Chemistry, Physics and Microbiology Volume 1: General Aspects. P. F. Fox, P. L. H. McSweeney, T. M. Cogan, and T. P. Guinee, ed. Elsevier, Amsterdam, the Netherlands.

Everard, C. D., C. C. Fagan, C. P. O’Donnell, D. J. O'Callaghan, M. Castillo, and F. A. Payne. 2007. Computer vision and color measurement techniques for inline monitoring of cheese curd syneresis. J. Dairy Sci. 90:3162-3170.

Fagan, C. C., M. Leedy, M. Castillo, F. A. Payne, C. P. O’Donnell, and D. J. O'Callaghan. 2007. Development of a light scatter sensor technology for on-line monitoring of milk coagulation and whey separation. J. Food Eng. doi:10.1016/j.jfoodeng.2006. 1012.1014.

Fox, P. F., and P. L. H. McSweeney. 2006. Advanced Dairy Chemistry. Vol. 2. Lipids. Springer, New York, NY.

Johnston, K. A., M. S. Luckman, H. G. Lilley, and B. M. Smale. 1998. Effect of various cutting and stirring conditions on curd particle size losses of fat to the whey during cheddar manufacture in ost vats. Int. Dairy J. 8:281-288. 
Johnson, M. E., C. M. Chen, and J. J. Jaeggi. 2001. Effect of rennet coagulation time on composition, yield, and quality of reducedfat cheddar cheese. J. Dairy Sci. 84:1027-1033.

Lagoueyte, N., J. Lablee, A. Lagaude, and B. T. DeLaFuente. 1994. Temperature affects microstructure of renneted milk gel. J. Food Sci. 59:956-959.

Lawrence, A. J. 1959. Syneresis of rennet curd. Part 1. Effect of time and temperature. Aust. J. Dairy Technol. 14:166-168.

Lawrence, R. C. 1991. Processing conditions. Pages 64-78 in Factors Affecting the Yield of Cheese. International Dairy Federation, Brussels, Belgium.

Lawrence, R. C., K. A. Johnston, and C. Honore. 1993. Cheese yield, quality and profitability. Pages 529-538 in Cheese Yield and Factors Affecting Its Control. International Dairy Federation, Brussels, Belgium.

Lucey, J. A. 2002. Formation and physical properties of milk protein gels. J. Dairy Sci. 85:281-294.

Lucey, J. A., and P. F. Fox. 1993. Importance of calcium and phosphate in cheese manufacture: A review. J. Dairy Sci. 79:17141724.

Marshall, R. 1982. An improved method for measurement of the syneresis of curd formed by rennet action on milk. J. Dairy Res. 49:329-336.

McMahon, D. J., R. J. Brown, G. H. Richardson, and C. A. Ernstrom. 1984. Effects of calcium, phosphate and bulk culture media on milk coagulation properties. J. Dairy Sci. 67:930-938.

Mellema, M., P. Walstra, J. H. J. v. Opheusden, and T. V. Vliet. 2002. Effects of structural rearrangements on the rheology of rennet-induced casein particle gels. Adv. Colloid Interf. Sci. 98:25-50.

Mishra, R., S. Govindasamy-Lucey, and J. A. Lucey. 2005. Rheological properties of rennet-induced gels during the coagulation and cutting process: Impact of processing conditions. J. Texture Stud. 36:190-212.

Najera, A. I., M. de Renobales, and L. J. R. Barron. 2003. Effects of $\mathrm{pH}$, temperature, $\mathrm{CaCl}_{2}$ and enzyme concentrations on the rennet-clotting properties of milk: A multifactorial study. Food Chem. 80:345-352.

O’Callaghan, D. J., E. P. Mulholland, A. P. Duffy, C. P. O’Donnell, and F. A. Payne. 2001. Evaluation of hot wire and optical sensors for on-line monitoring of curd firmness during milk coagulation. Irish J. Agric. Food Res. 40:227-238.

Payne, F. A., C. L. Hicks, and P. S. Shen. 1993. Predicting optimal cutting time of coagulating milk using diffuse reflectance. J. Dairy Sci. 76:48-61.

Sharma, S. K., A. R. Hill, and G. S. Mittal. 1993. Effect of milk concentration, $\mathrm{pH}$ and temperature on aggregation kinetics and coagulation properties of ultrafiltered (UF) milk. Food Res. Int. 26:81-87.

van den Bijgaart, H. J. C. M. 1988. Syneresis of rennet-induced milk gels as influenced by cheesemaking parameters. PhD Thesis. Wageningen Agricultural Univ., Wageningen, the Netherlands. van Vliet, T., H. J. M. van Dijk, P. Zoon, and P. Walstra. 1991 Relation between syneresis and rheological properties of particle gels. Colloid Polym. Sci. 269:620-627.

Zoon, P., T. Vanvliet, and P. Walstra. 1988. Rheological properties of rennet-induced skim milk gels. 2. The effect of temperature. Neth. Milk Dairy J. 42:271-294. 